\title{
Application of Skopos Theory in C-E Translation of Quanzhou- Specific Chinese Terms
}

\author{
Wang Caiying \\ School of Foreign Languages, Quanzhou Normal University, \\ Quanzhou, Fujian, China,362000
}

\begin{abstract}
This paper discusses the C-E translation of the culture-loaded items in Quanzhou,China. It includes three parts. The first part is Quanzhou's general introduction and the classification of its culture; the second part discusses the concept of culture and theoretical issues; the last part addresses the methods to translate them readable,understandable and be faith to the original to the most extend.
\end{abstract}

Keywords: Quanzhou; culture-loaded items; translation methods

\section{INTRODUCTION}

Globalization witnesses an unprecedented increase not only in cross-border economic activities but also in cultural interactions. Quanzhou, known as the "World Religious Museum", the world's first "World Multicultural Exhibition Center" and "Culture City of East Asia", is also the source of Minnan (southern Fujian) culture and multi-ethnic area. Today,over 5 million Overseas Chinese, and 40\% of Taiwan's Han Chinese, trace their roots to Quanzhou. Therefore, Quanzhou was a melting pot and simultaneously a bundle of culture-specific items emerge which are ubiquitous and indispensable in the daily life, yet they have also given rise to a slew of translation problems. Today,Quanzhou's booming economy, abundant cultural heritages and Minnan (southern Fujian) unique customs are attracting more and more foreigners to come to Quanzhou to invest and visit. As a result, the correct and effective translation of culture-specific items of Quanzhou is conductive to its development and the foreigners.

The present paper lays emphasis on the culture-loaded elements in Quanzhou,China. First, previous studies have been reviewed,and then Quanzhou's distinctive culture is introduced. Second, Skopostheorie is discussed and applied it to translate Culture Specific Items (CSIs) in Quanzhou. Finally, three suggestions are come up with to supplement the aforementioned discussion. Therefore, this research will shed some light on the translators and scholars who want to do some translation research of Chinese culture-specific items and those who will invest or pay a visit to Quanzhou.

\section{LITERATURE REVIEW}

What is Culture Specific Items (CSIs)? In 1996, the Spanish translator Javier Franco Aixelá proposed the term"culture-specific items" (CSIs) and defined it as "those textually actualized items whose function and connotations in a source text involve a translation problem in their transference to a target text,whenever this problem is a product of the nonexistence of the referred item or of its different intertextual status in the cultural system of the readers of the target text."(Aixelá, 2007:58)Culture Specific Items (CSIs) are "those that do not exist in the target text or have a different inter-textual status"(Esmaeil Bagheridoust,2017). In Newmark's opinion,CSIs are associated with 
a particular language and cannot be translated literally. From these definitions,it can be found that CSIs have distinctive nation-oriented or region-oriented features,posing difficulties in understanding and translating them.

During 1980s, the cultural turn emerged, some translation theorists,such as Bassnett, Lefevere, Lambet and Robyns, began to study the translation problems from the perspective of culture. They viewed translation as a kind of communication between two cultures. "They go beyond language and focus on the interaction between translation and culture, on the way in which culture impacts and constrains translation and on the larger issues of contexts, history and convention...(Munday,2001:127) Researchers and scholars(Aixelá,2007:61-78;ZHANG Nanfeng,2004:18-23) came up with some translating strategies in accordance with E-C translation,such as repetition, deletion, limited univasalization, extratextual gloss, intratextual gloss, natrualization, deletion, autonomous creation and so on. XIA Qing(2010:62)summarized and analyzed Hawkes and Yang employed the following translating strategies: linguistic translation,transliteratation, extratextual gloss, intratextual gloss, absolute univasalization, naturalization, deletion to translate the CSIs of the ancient Chinese official system in Hong Lou Meng. Zsuzsanna Ajtony(2017:85)employed two translation strategies-retention and intervention to translate the CSIs in national dishes,food glossary and some other things in the tourism and hospitality industry. With the increasing integration of economies,it is the time to give people smooth translation of Quanzhou's culture.

\section{THE GENERAL INTRODUCTION OF THE CULTURE OF QUANZHOU}

Quanzhou, also named Zaytun (an Arab name, a homonym for "olive", symbol of peace) or Wen Ling, was once the largest harbor during the Song and Yuan(1206-1368) dynasties, which was linked with more than 100 other ports along the Maritime Silk Roads. Praised as "the Alexandria of the East" by Marco Polo, it was a legendary port visited by a number of famous medieval explorers, such as Friar Odoric of Pordenone and Ibn Battuta and so on. Over centuries,merchants,diplomats, and missionaries from foreign countries and other ethnic groups (48 ethnic groups out of 56 ethnic ones)all over the country coexisted, intermarried and learned from each other,Quanzhou has been a "World Multicultural Exhibition Center". Population's migration and economic exchange make Quanzhou's culture diversity which is deeply colored by local particulars of all types.

\section{Minnan dialect (方言文化 fangyan wenhua)}

Originated in Quanzhou, Minnan dialect was spread to other provinces in China and the world Chinese areas because of migrations from generations to generations. Today's Minnan dialect has become one of the representatives of the 60 major languages of the earth .

\section{Religious culture (宗教文化 Zongjiao wenhua)}

As is known to all, "The foreigners who flocked to ancient Zaytun(Zayton) exchanged not just commodities but cultures, philosophies, and religious" (潘维廉,2003:29)and Zayton's open to foreign religious. Quanzhou was dubbed a "World Museum of Religion" by UNESCO, because Quanzhou has been noted for its many religions and rich well-kept religious relics left by Catholicism, Buddhism, Islam, Christianity, Hinduism, Manichaean and Judaism, Taoism, Nestorianism, Brahmanism, Jainism, Zoroastrianism, Mazu worship, and Confucianism can be found in Quanzhou today. We can enjoy these eye-opening bilingual exhibits in Quanzhou Maritime Museum which witnessed ancient Quanzhou's pivotal role in both domestic and international affairs. 


\section{Architecture culture (建筑文化 jianzu wenhua)}

Quanzhou's rich culture manifests itself in its unique ancient architectural complexes like folk residences, bridges, temples and stone towers. Among them, Qingjing Mosque (Ashab Mosque) is the oldest stone Mosque in China, boasting the unique style of typical Arabic-Islamic architecture which was renovated in 1310(Yuan Dynasty). Anping stone Bridge, one of the three famous bridges in Quanzhou ,was the longest bridge on earth during the Middle Ages, and is still the longest stone bridge today.

\section{Cuisine Culture (饮食文化 yinshi wenhua)}

Since Quanzhou is situated in the subtropical zone along the coasts and rivers, ringed by mountains, it is blessed with unparalleled food materials. Moreover, Quanzhou is a melting pot where deft cooks invent and improve many local delicacies. Quanzhou is gradually famous for its unique and tasty cuisines which features light food and delicious snacks.

\section{Folk Culture (民俗文化 minshu wenhua)}

Quanzhou is a world multicultural center and a multi-ethnic area where 48 ethnic minorities are living harmoniously with the Han. After a long period of communication and integration, Quanzhou folk culture shows the distinctive personality and colorful characteristics, including festival folk culture, such as "Festival of liberating all living creatures from worldly sufferings" (pudu); the opera cultural heritage, such as traditional puppet shows, Southern Drama(nanyin), Liyuan opera, Gaojia Opera. Quanzhou also has many unique crafts, such as puppets, clay sculptures, porcelain, paper weaving, Hui'an's stone carving and so on. Quanzhou retains folk music, operas, dances, puppet, Chinese Wushu performances, folk arts and crafts.

\section{Overseas Chinese Culture (华侨文化 huaqiao wenhua)}

Quanhou is a famous hometown of Overseas Chinese and Han compatriots in Taiwan province. According to incomplete statistics, about 7 million Overseas Chinese in Hong Kong, Macao and other 129 countries and $40 \%$ of Taiwan's Han Chinese trace their roots to Quanzhou. Thanks to a couple of decades of dramatic reform and opening up, Quanzhou is becoming once again a global commercial and cultural crossroads. These Overseas Chinese make great contributions to the renovation or construction of schools, hospitals, churches, temples, bridges, roads and exchange culture.

\section{Trademark Culture (品牌文化 pinpai wenhua)}

Quanzhou witnessed radical development of economy in the past years, and a large amount of goods are exported to the foreign countries. Well-known brands and makes play a crucial part in developing international market. Quanzhou is designated as one of "The Brand Capital of China".

\section{THE SKOPOSTHEORIE AND ITS APPLICATION IN C-E TRANSLATION OF QUANZHOU- SPECIFIC CHINESE TERMS}

Because of the differences in the social systems, natural environments, religions, beliefs, customs, ways of thinking, psychological differences and language habits of different countries and nations, as well as language inextricably interwoven with culture, translation is not only a language conversion activity, it is also a deep cultural exchange. However, the implied cultural connotation of language brings various obstacles to translation, as a consequence of which requires the translators to adopt some translation strategies to adapt to the context of cultural factors.

Skopostheorie was established by German linguist Hans Vermeer(1930-2010) on the basis of modern linguistics-pragmatics linguistics, language behaviorism, text-linguistics and the 
aesthetics of reception. This theory lays emphasis on the purpose of the action of translation and inviting an appropriate method to produce a functionally and communicatively adequate, accordingly, adequacy is the assessment criteria for translation action. Skopostheorie constitutes the following rules: skopos rule, coherence rule, fidelity rule, loyalty principle.

\section{Obey the Skopos Rule}

According to Skopostheorie, the intended purpose of the target text should be given due consideration, and thus determining the translation methods and strategies. Let me raise the following example:

Example 1: 土笋冻

Translation 1: tu sun dong

Translation 2: sea worm jelly

Translation 3: sipunculid worm jelly

Translation 4: soil bamboo jelly

Translation 5: Jellied Tusun, a kind of seafood

“土笋冻（tu sun dong）" is a famed flavor snack in southern Fujian and the target readers of its translation are the masses from all walks of life. The translation aims to inform the foreigners of the ingredients and attracting them to taste the snacks. To some degree, translation 1 to translation 5 can't attend to their needs. Translation 1 is translated by Chinese Pinyin and translation 4 is Chingish, these translations are a total failure in that they make no sense to foreign readers. Translation 2 and 3 are partial failures seeing that the word "worm" may make the readers have disgusting association; moreover, "sipunculid" is a formal word which may be strange for some readers. Translation 5 is a good translation because it takes the target readers' needs into consideration: the common words ease their reading burden and "Jellied" and "seafood" give them clear information of this snack. Evidently, the translation effort of version 1 to version 4 involves no consideration of the intended readers, thus causing communicative failure.

\section{Obey the Coherence Rule}

Word-for-word translation obeys the fidelity rule, while sometimes the target readers may misunderstand what it means, consequently, it can't achieve the communicative purpose. The following example is the case in point:

Example 2:郑成功 (Zheng Chenggong) Koxingga

Translation 1:Koxingga

Translation 2:Zheng Chenggong

Zheng Chenggong(郑成功),whose hometown was Quanzhou, was a hero who wrested control of Taiwan from the Dutch invaders, because of this contribution, the emperor gave his family name to Zheng Chenggong. However,in western history books, Zheng Chenggong was called “Koxingga". Koxingga (国姓爷) is regarded as successful because it is in line with the target readers' culture and it is also sufficiently coherent with the communication purpose.

\section{Example 3:}

Original:羽仙岩, 今老君岩。据明《闽书》载：“羽仙岩，在罗山、武山之下。”相传，老子 骑青牛西出函谷关，云游至此显圣成像，得名。《泉州府志》有载：“其地有石天成，略见头 目之状”。

Translation:Yuxian Rock is currently named the Stone Statue of Laozi. According to Min Book of the Ming Dynasty, Yuxian Rock is located at the foot of Mount Luo and Mount Wu. It is said that Laozi rode a black ox, leaving Hangu Pass for the west. When arriving here, he was 
transfigured and became an immortal, hence named Yuxian Rock. In the Annals of Quanzhou Prefecture, "The stone here was formed naturally, one can quickly catch a glimpse of its head, eyes and beard".(cited from the introduction of Qingyuan Mountian)

Analysis: Laozi, also called Lao Dan, is the first philosopher of Chinese Taoism and the alleged author of Tao Te Ching. He has been respected and worshiped in all circles in China, but he may be a little strange for some foreign tourists if only translated by Pinyin. After transliteration, intratextual gloss can be employed to help the target readers' understand the source language.

\section{Example 4: 古厝茶馆(Gu cuo chaguan)}

“Gu cuo Teahouse" (Gu cuo chaguan) is a teahouse in an age-old house. 厝(cuo), an old house in Minnan dialect, is a distinctive traditional dwelling in southern Fujian,which embodies the soul of every family member in a red brick house and inherits the glory of home. 古厝茶馆( Gu Cuo Chaguan) means a teahouse in an old building, so as the name of a shop, it can be translated into "Gu Cuo Teahouse" for its conciseness and distinction or "Gu Cuo ( an age-old house)Teahouse" in tourism materials by reason that the contents in brackets may tell the readers the information of the “古厝”.

\section{Obey Fidelity Rule}

The core of fidelity rule is that the target version and the source text should be faithful in intertextual coherence which doesn't require a word-for-word translation while it should transfer the full meaning of the source text. An incoherent version is often hard to understand, and may be interpreted in different ways.

\section{Example 5:照墙“紫云屏”}

Translation: Zhao Qiang“Violet Cloud Screen”

"Zhao Qiang" (a short screen wall facing the gate of mansion)lies in front of Quanzhou Kaiyuan Temple. It is also called the "Fen Wall" ("power wall") which is a symbol separating the cleanfresh Buddhist land from the dusty world. According to WordNet, the connotation meaning of "Purple" is "belonging to or befitting a supreme ruler", on the other hand,the connotation meaning of "violet" is "a shy person". As we all know,Buddhist sites are solemn place, so "purple" best suits Chinese and English contexts. This example expounds that the word or phrase in translated version will not in accordance with the connotation and/or denotation of the source text.Avoiding misnomer should be kept in mind when translating to achieve a good communication effect.

Derived from a legendary story in China,“青牛” in Example 3 referred to a ferocious animal and was later emasculated by Laozi, that is , “a black ox" isn't an equivelant of “青牛” because the English version "a black ox" simply accord to the superficial meaning of the source text and doesn't give a deep consideration to the meaning of the source text.

Example 6: 贵人鸟

Translation: guirenniao

贵人鸟(guirenniao) is an enterprise in Quanzhou engaging in sports garments and its trademark is "guirenniao" "guirenniao" is Chinese phonetic alphabet which differs from English, so it may weigh heavy burden on the target readers' spelling and understanding. What's more, “guirenniao" doesn't present the implied meaning of “贵人鸟”in Chinese context“贵人鸟”was a legendary story depicting “the memorable but had to be separated feeling”. 
“Noble Bird” may be a better translation for “贵人鸟”,for translation by Pinyin will undermine the strengths and competition of this company on the international market and fail to serve the interests of the potential customers.

It is not difficult to find a vast number of Quanzhou local trademarks be transliterated,such as ( 鸿星尔克)Hongxingerke，（好舒爽）HaoShuShuang，（申鹭达） Shenluda，（贵人鸟） GuiRenNiao, (铁观音) Tieguanyin, (福时来) FUSHILAI. These transliterations can not bring any beautiful feelings and good associations to foreign consumers, except as a symbol of allegations. What is more, these enterprises' business philosophy and the cultural implication in Chinese marks can not be passed on to foreign consumers. Therefore, the English translation of trademarks should avoid using a long Chinese pinyin as their English names.

\section{FURTHER DISCUSSION}

From the perspective of Susan Bassnett, "Translation is more than a simple transfer of languages; it is an act deeply rooted in the cultures of languages. Translation is both the translation the intracultural communication and the inter-cultural communication. The basic unit in translation should be "culture" rather than "text". (Cited from A Coursebook of Chinese and Western Translation Theories:243). Translation is not just a process of decoding and recoding, especially for those culture-loaded source texts. Consequently, on one hand, the translator should spare no efforts to introduce and disseminate the culture in the source language to contribute to cultural transmission and to protect cultural diversity; on the other hand,the translation version should achieve the functional equivalence in the target language culture and make it readable. Based on the aforementioned two facets, when translating, the following three aspects must be kept in mind.

\section{Unify the translation names}

As the saying goes, there are thousand Hamlets in a thousand people's eyes, Chinese culturalloaded names are no exception. The same Chinese cultural-loaded elements may have different interpretations because of different understanding of translators and different translating strategies and purposes, which may make foreign readers confused. For example, 老君岩 has the following translating versions: Laojun Rock, the Stone Statue of Laozi. In the authorized translation version, it is better to use the same translation name for the same place.

\section{Avoid ambiguity}

Because of the great differences between Chinese and English, difficulties may arise when there is little or no awareness of divergent meaning of some words and phrases. For example, a trademark is the hallmark of the quality, credibility, corporate reputation and image, so emphasis is often laid on its name. “拼(pin)”is a trademark of men's garment in Quanzhou and its English trademark is transliterated into "Pin". “拼(pin)"in Chinese, especially in Minnan dialect, means people endeavor to achieve success, while "pin" in English has diversified meanings in its denotation and connotation, which may undermine the readers' understanding. Therefore, the translation of "Pin" will make foreign readers have bad associations or ambiguities, which should be given the first priority. In effect, the preferential translation can not only contain all the meanings of the Chinese trademark, but also in line with foreign cultural values and beliefs and the like. “安踏(anta)"sets a good example. It is a trademark of ANTA Sports which produces footwear, apparel and accessories. ANTA Sports adheres to the business philosophy " Reliable business, practical man, a century-old brand", In Greek, Anta means "The God of Land" who will give you strength and safety when you are wearing ANTA shoes, Therefore ANTA has good associations both in Chinese and English. 


\section{Publicize Chinese traditional culture and make the foreigners readable}

We shall present different strategies applied in the translation of culture-specific items.On one level,with the development of economic globalization, the world tends to be cultural diversity, and therefore time has been come to retain and highlight the unique charm of each culture,so has Chinese traditional culture. When translating, the translator should adopt the suitable strategies to make sure that the original cultural references are retained. On another level, the target readers also can read between the lines.The following sets a good example:

Example 7:盘龙, aka Panlong, aka Coiling Dragon, is a webnovel by popular Chinese Xianxia (fantasy/kung fu) writer I Eat Tomatoes (我吃西红柿) 1.

It is the first sentence on the first page of the fiction Panlong, the first fully-translated-intoEnglish webnovel which is gained popularity among English native readers.There are two Chinese words (sentences): 盘龙 and 我吃西红柿 in this sentence and several translating strategies are employed:First,the title of "Panlong" is translated as "aka Panlong, aka Coiling Dragon", in which "aka"is an acronym for "also known as", "Panlong" by Chinese Pinyin, and" Coiling Dragon" by literal translation. Second, "Xian Xia"is first translated by Chinese pinyin "Xianxia", and then "fantasy / kung fu" supplement its meaning. Third,the writer's name is literally translated into"I Eat Tomatoes", followed by “我吃西红柿”. The combination of Chinese characters,transliteration,literal translation retains Chinese culture elements, especially the Chinese characters arouse the foreign readers' interests to study Chinese $^{2}$,and free translation is conductive to the target readers' understanding, avoiding stiffness.

\section{CONCLUSION}

Quanzhou is a multicultural center in China, and its culture-specific items are a unique linguistic phenomenon,which do hamper the communication between two languages in some way. In this paper, the definition of CSIs is given, Quanzhou's unique culture are introduced; some examples are raised to be further discussed under the guidance of the Skopos theory; in addition to the main Skopos rules, coherence rules and the fidelity rule are indispensable in judging the success of translation and the transmission of CSIs. In a word,before translating, the translators should read between the lines,that is to say,take the connotation and denotation of these words into consideration; when translating, the translators should employ the most suitable ways to transfer the culture in source language and highlight the target recipients' needs, so one or two or the combination of translation strategies can be applied to achieve the best effect in form as well as in meaning. Simultaneously,in a culturally diverse world, the translator must have the awareness of cultural self-confidence and maximize the transmission of his own culture.

\section{References}

Aixelá, Javier Franco.(2007).Culture-Specific Items in Translation. Translation Power Subversion.

Esmaeil Bagheridoust.(2017).Translation of Culture Specific Items: A Case Study of Persian Architecture Terminology. International Journal of Applied Linguistics \& English Literature.(2)

Munday,Jeremy. (2001). Introducing Translation Studies,London: Routledge.

Román Avarez and M. Carmen-Africa Vidal eds. Beijing: Foreign Language Teaching and Research Press.

William N·Brown. (2003). Mystic Quanzhou,Xiamen:Xiamen University Press.

\footnotetext{
${ }^{1}$ http://www.wuxiaworld.com/cdindex-html/book-1-chapter-1/

${ }^{2}$ http://www.360doc.com/content/16/1027/11/36963884 601755648.shtml
} 
Xia Qing. (2010).On English Translation of Culture-Specific Items in the Ancient Chinese Official System:A Descriptive and Comparative Study on Hawkes' and Yangs' English Translated Cases of Hong Lou Meng. Cross-Cultural Communication,(4).

Zhang,Nanfeng.(张南峰). (2004). A Critical Introduction to Aixelá Strategies for Translating CultureSpecific Items. (艾克西拉的文化专有项翻译策略评介). Chinese Translators Journal(中国翻译). (1).

Zsuzsanna Ajtony. (2017). Cultural Interchangeability? Culture-Specific Items in Translation.Acta Universitatis Sapientiae Philologica, (2). 